\title{
THE BULLYING PHENOMENON IN THE SCHOOL ENVIRONMENT
}

\author{
Adina NICHITA, Dumitru ENACHE, Rebecca-Eunice PELMUS,, \\ ${ }^{1} \mathrm{MSc}$, Faculty of Environmental Engineering and Food Science, Valahia University of \\ Târgoviște, ${ }^{2} \mathrm{MSc}$, Faculty of Electrical Engineering, Electronics and Information \\ Technology, Valahia University of Târgoviște, ${ }^{3} \mathrm{MSc}$, Faculty of Sciences and Arts, Valahia \\ University of Târgoviște, \\ Romania. \\ E-mail: ${ }^{1}$ nichitaadina79@gmail.com, ${ }^{2}$ ing.dumitru.enache@gmail.com, \\ ${ }^{3}$ rebecutza2014@yahoo.com
}

\begin{abstract}
Bullying represents a phenomenon that manifests itself in most schools around the world, and in recent years has received increased attention from teachers, educational policymakers, and other people involved in education. The approach to bullying has become a topic of global interest, especially by understanding its significance, ways of manifestation, but also methods to prevent and combat or reduce it. This paper focuses on the comparative analysis between two European countries, Italy and Romania, which are ranked second and third in Europe on the phenomenon of bullying in schools. The paper includes theoretical notions about this phenomenon, figures taken from studies conducted in Italy and Romania on the phenomenon of bullying, a comparison between the two countries, statistics based on a questionnaire administered to a sample of students in Dâmbovița County Romania, such as and proposing measures to prevent and combat or reduce the phenomenon, depending on the hypotheses of the study and the results obtained from the application of the questionnaire. The purpose of the investigation is to obtain a clear presentation of bullying, to highlight the situation that both education systems are going through, to obtain feedback from the questionnaire applied to a sample of students and to identify and propose concrete ways, to prevent, reduce and combat bullying in the school environment, in order to increase the quality of education.
\end{abstract}

Keywords: aggressor; victim; bullying; types of aggression; prevention; mitigation; combating actions;

\section{INTRODUCTION}

Bullying is a form of violent and intentional social behavior, of a physical and/or psychological nature, repeated over time, which may seem discouraging to people who are victims, considered easy targets or unable to defend themselves. The term bullying is intended to define an aggressive, repeated behavior towards people who cannot defend themselves and who become victims of the aggressive person. Usually, the roles in bullying are well defined: on the one hand, the aggressor, who has a violent physical or psychological behavior, and on the other hand, the victim, who is subjected to the aggressive behavior.

In general, the phenomenon of bullying in school is "a category of aggressive behavior that involves an imbalance of power, the aggressive act being repetitive" (Olweus, 1991; 
Smith, \& Thompson, 1991), but also it is "a deliberate, repetitive act that involves negative actions against others, performed by a group of people or a person who has a social status superior to the victim(s)" (Olweus,1993).

Psychological suffering and social exclusion are the most common feelings in children, they do not want to find themselves in the situation of laying the role of the victim, who is repeatedly subjected to be humiliated by the aggressor. The main characteristics that allow us to define a situation with the label of "bullying" are: the aggressive behaviors manifested intentionally, the aggressive actions in a systematic way - physical or psychological -, which can lead to acts of persecution. So, an action is not enough to be able to impose the bullying situation, but the power asymmetry between the victim and his persecutor is recorded. Bullying represents a serious and common problem in the Italian and Romanian schools, but also in many other schools from Europe.

The aggressor's motivations can be different: the need to dominate, the feeling of superiority, the desire to become the group leader, jealousy, defending the honor of the family, the desire to form a close circle, the possibility of being a victim. Practically, bullying can be defined as "an intentional, malicious form of proactive aggression. It differs from other types of violent behavior, is repetitive and is characterized by a real or perceived imbalance of power, in which the victim is defenseless." (Arseneault, Bowes, \& Shakoor, 2010).

The victims deny the events, minimize them, especially due to the fear, making it difficult to identify the aggressor. The victim is poorly motivated, has low self-esteem, is discouraged from school, is afraid, has somatic disorders such as stomach pain, anxiety, decreased school performance. They tend to isolate themselves, not understanding why such things happen. Usually, they do not share the problem, they tell after a while when there are serious consequences on self-esteem and they do it because it is not easy to hide the consequences. More, the victims talk to their best friends, few of them talk to their parents or teachers.

In some cases, victims directly express suffering (especially to parents), or through inappropriate behavior (irritation, anxiety, aggression, self-harm, destruction of objects, dropping out of school). Some victims accept the treatments of the psychologist/psychiatrist, others refuse to benefit from out-of-school treatments. Sometimes the victims do not return to school.

Students who watch what happens without helping the victim are usually classmates who pretend not to notice and are not willing to talk. Generally, those people do nothing, especially for the fear that they may be victims.

\section{THEORETICAL FRAMEWORK}

\subsection{General notions}

Nowadays, bullying represents a phenomenon that worries many European countries and beyond. As an example, in Italy, surveys indicate that one of two children is a victim of bullying. The age with the highest risk is between 11 and 17 years, even the most critical period is between 11 and 13 years: at first, insults, mocking words, followed by ridicule on the physical appearance, and according to the ISTAT study, in four out of ten cases, beatings, kicks, and punches. (Redatione Salute, April 2018) 


\subsection{Several causes of the bullying phenomenon}

The underlying causes of bullying are multiple and take into account several individual factors and group dynamics such as the child's temperament, family patterns, stereotypes imposed by the media, or education shared by parents and schools. The motivations that can lead to cases of bullying can be multiple:

- $\quad$ lack of rules: in places where the rules are not followed.

- $\quad$ lack of supervision: the saying "when the cat is not at home, the mice play on the table" is valid.

- $\quad$ social boredom: lack of stimuli, dissatisfaction, monotony - can sometimes push children to find stimuli in negative behaviors.

- $\quad$ attraction of power and superiority of the aggressor: the desire for power is old history, everyone wants to be leader, to be important, to be in the front line. Whoever is a follower of this idea does not stop in front of anyone, using any means by which can dominate.

- pleasure of dominating - to dominate someone else, forcing, humiliating, pleasing to put a person in a condition of inferiority. People who have these sick feelings perform inappropriate actions and behaviors.

- belonging to the group of people or alliances of people - sometimes the alliance of people can be very dangerous. Even a person who behaves normally, if he allies himself with a group of alliances of people, can commit actions that he would not normally do.

- $\quad$ envy - some people would do their best to turn a situation to their advantage.

- $\quad$ antipathy towards certain people - often trying to find in bullying particular motivations, instead it is nothing more than simple antipathy (showing a hostile attitude and behavior towards him/her, of social exclusion).

- $\quad$ intolerance of difference - one of the most common motivations in bullying is intolerance of who is perceived as different, without the victim doing anything wrong, just for the simple fact that he/she is different: e.g. homosexual, foreign (not necessarily as a nationality, but also as a county, region, north and south, skin color, disability, belonging to a different culture or religion etc.). Usually, those attitudes are exacerbated by dangerous positions such as those related to the religion of different categories, homosexuality, emigrants, they have a different culture. Most of the time intolerances are born in the family.

- feeling great - many teenagers want to prove that they are older than they really are and often do to feel like their older colleagues... And what is the best way to prove if not by force? To show others that they are brave, strong, careless, even if it means beating a weaker colleague to prove that he/she is a leader.

- $\quad$ physical strength - being aware of one's physical strength does not mean that one can do what he/she wants.

- $\quad$ sensitivity and fear of the victim - it seems a paradox, but if a child is strong and confident, he/she does not risk being intimidated. The fact of being sensitive, fearful, inconstant can determine the arrogance of the aggressor.

- $\quad$ lack of maturity, responsibility, and morality of the aggressor - the aggressor does not demonstrate morality, then how could he/she respect others or the victim in particular? 
- $\quad$ pleasure of making others suffer - some teenagers feel pleasure in seeing that another person is suffering, they take pleasure in seeing that the other has lost, they sometimes enjoy even without limit.

- $\quad$ inadequate family education styles - many education styles can be a source of discomfort and / or inappropriate behavior.

The children of the $21^{\text {st }}$ century have higher and higher demands. We can often hear: "My child must have everything I didn't have!" - a tablet at 6 years old, a car at 18 years old, SUV at 20 years old etc. When they do not get what they want, they start crying, screaming, kicking and kicking their parents, grandparents etc. How can a child who uses violence to get what he wants, even with adults, role models, not use violence with colleagues when they fail to get what they want? To find reliable solutions we need to ask ourselves some questions, like: "What is bullying?", or "What are the causes of bullying?", or "And how can we correct it?".

Bullying represents a form of repression by children, which can cause inconvenience to other more sensitive, weak, victimized children who do not know how to defend themselves. The victim is usually humiliated, intimidated. The aggressor's behavior begins by injuring the victim, both verbally and physically. After the victim is humiliated, he/she is no longer the person he/she was before this event: the child refuses to go at school, to avoid other abuses, feels guilty because he/she attracts negative behaviors, loses self-esteem, security and self-confidence.

An important cause is the lack of support from teachers and parents. Also, nowadays, for example, certain violent video games encourage aggressive behavior and subtly induce children to bully, to act aggressively. As an example, in Italy, the Ministry of Education does not recommend the purchase of such videogames that contain scenes of violence, conditioning certain young people who are already prone to violence. Injury to the victim's self-esteem is metabolized over time and can cause the person to experience a great disregard for school, to such an extent that the victim can also become an aggressor. As we have seen, the causes and factors that can cause acts of bullying are multiple. Possible solutions to put an end to the inappropriate behavior of the aggressor can be:

- $\quad$ communicate to teachers and parents what is happening;

- $\quad$ encourage the students who saw what the aggressor was doing to speak out;

- $\quad$ encourage the abused student, to speak out action performed by the parents;

The first efficient answer lies in the way of educational operation of the adult, the teachers having the duty to collaborate, but also to cooperate with the students' families, to intervene with the same firmness on small and large aggressions.

Those for whom this educational intervention is intended are not only the aggressor and the victim, but also the whole class group, including those who take a neutral position trying not to be involved (spectators).

\subsection{Statistics from Italy}

A close connection between family, school, institutions and strong supervision on social media, was the proposal of the Ministry of Health, through Beatrice Lorenzin, as an opposition to the phenomenon: “... We must raise awareness of both children and parents on bullying acquis. We need to work on respect for ourselves, respect for others, and respect for the rules." 
This issue is by no means negligible. ISTAT data (Redatione Salute, April 2018) found that in 2014, more than 50\% of children aged 11 to 17 had certain offensive behaviors, both verbal and physical, from other colleagues during the school year. The percentage is higher of children aged 11 to 13 years, approximately (22.5\%), adolescents aged 14 to 17 years have constantly suffered offensive, humiliating, and violent behaviors $(17.9 \%)$. The victims of the bullying phenomenon are mainly girls $(20.9 \%)$, followed by boys $(18.8 \%)$. Instead, the most numerous victims are in high schools $(19.4 \%)$, followed by vocational schools $(18.1 \%)$ and technical institutions $(16 \%)$. There are also differences between the northern and southern regions of Italy: the phenomenon is more widespread in the northern regions of the country, 23\% targeting children aged 11-17; the percentage exceeding $57 \%$ in cases of bullying that come regularly.

According to the same study, the most common violence is represented by insults $(12.1 \%)$, slander, derision of physical appearance or manner of speaking $(6.3 \%)$, denigration (5.1\%), exclusion for their own opinions $(4,7 \%)$, aggression with pushing, beating, kicking and punching $(3.8 \%)$. The phenomenon persists and refers not only to classmates but also to violence and threats against teachers. The data speaks for itself: in Italy, there is on average a case of bullying every day. This figure is given by the emergency calls of the Blue Phone in 2017. 10\% of the requests for help were addressed to the Association that deals with bullying - 46\% come from northern Italy, followed by southern Italy and the island of Sardinia with $31 \%$ and $23 \%$ respectively. The latest data indicate that students' aggression against their teachers is commonplace. In fact, based on what about seven thousand middle school and high school students told Skuola.net, the phenomenon is less serious than previously thought. Only $7 \%$ of students stated that they witnessed an aggressive reaction of a colleague to the teacher. We are talking about a ratio of 1:20. In most cases, there is talk of verbal aggression: $55 \%$ of those interviewed reported that the aggressor was limited to insults. In more than a quarter of those incidents (36\%), the student resorted to violence, raising his/her hand to the teacher; in absolute terms, this is translated into few episodes of this type. 354 teenagers were victims of aggression in 2017. It is a problem that has not been given due attention, and now attempts are being made to remedy it.

The data collected by Skuola.net and the National Surveillance are: $28 \%$ among high school students are victims of bullying and the percentage is $30 \%$ for middle school students. The percentage is increasing compared to 2016 when the percentage was $20 \%$. Only $1.8 \%$ of the victims are persecuted online, the vast majority suffering violence, humiliation every day. The consequences of this violence lead to depression (75\% victims), crying crises (54\%), acts of self-aggression (32\%), and suicide (46\%). A percentage that scares and invites us to reflect on this phenomenon, realizing that the research subjects represent adolescents aged between 11-18 years.

The data of the National Center for Listening to the Blue Telephone, in Italy, concerning the school year 2015-2016, highlighted the following (S.O.S. Il Telefono Azzurro Onlus, 2016):

- in the 2015-2016 school year, the Blue Telephone took over on average one case per day of bullying and cyberbullying episodes, based on the 19696 and chat phone lines. In total, the cases taken over were 270 (the total number of cases taken over by the Association was 13\%, a higher percentage than that between February-July 2015, which was $10.3 \%$ ); 
- from the 270 cases taken over, $62 \%$ concerned requests for assistance regarding bullying, and $10 \%$ were requests for assistance concerning cyberbullying;

- more than half of the reported cyberbullying cases came from northern Italy, in $56.5 \%$;

- mainly, the victims of bullying are students (89.5\%), more than one girl in 6 is the victim of cyberbullying (16.7\%);

- the age of victims decreases: there is an increase in victims among young children, even 5 years old ( $22 \%$ of cases);

- the requests for help in cases of episodes of cyberbullying start with high school and continue with adolescence ( 1 from 2 requests involve adolescents);

- the prevalence of victims of Italian nationality is reconfirmed (data around $85 \%$ of cases);

- the aggressors are generally boys, in about $60 \%$ of cases;

- most episodes of bullying and cyberbullying occur in schools (82\%)and online (7\%).

With the introduction of Law no. 71 (May 29, 2017), and its publication in the

Italian Official Gazette (17.07.2017), the Parliament approved new provisions on the protection of children who are victims of cyberbullying.

The objective of this law is to combat this phenomenon, by adopting preventive actions and punishing those responsible. This law allows the condemnation of acts of bullying, acts of defamation broadcast online that violate privacy. (Open Your Wings, 2018)

\subsection{Statistics from Romania}

A study conducted by Save the Children Romania, made in 2016, related to the situation of the bullying phenomenon in the Romanian school environment, highlighted the following aspects:

- 2 out of 10 children reported co-deaths of exclusion from a group by other students, so $31 \%$ of students said they were declared excluded from group activities, and another $23 \%$ received the promise of exclusion from the group.

- the cases of the humiliation of students in front of others are presented with a percentage of $23 \%$, while $37 \%$ of students who endured negative words spread in the school.

- in situations of physical bullying, the data show that $13 \%$ of students had the destruction of property by other students, $30 \%$ of students said that they were repeatedly hit by students at school, in the situation of assisting a case of bullying, $78 \%$ of students highlighted this fact.

- $68 \%$ of cyberbullying cases are reported, most of which take place on social networks.

In the same study, it is mentioned the research conducted by the World Health Organization $(W H O)$, where the results illustrated the situation of children of different ages, so the first category is that of 11-year-olds who assaulted other students several times in the previous month with a percentage of $17 \%$, for children who are older, respectively 13 years and 15 years, being $23 \%$ - it results in a difference of $6 \%$ between those two percentages. The data processed for this situation - provided by the Ministry of National Education - for the 2014-2015 school year, indicated 18,783 cases of violence, at the national level. 


\subsection{A parallel between Romania and Italy}

Presenting the situation in Italy - extracted from the ISTAT study - and the situation in Romania - described by the Save the Children Romania study -, a comparison was interested to be made, concerning the situations recorded in both countries. In this respect, figures 1 and 2 offer an image of the incidence of bullying on two age ranges, respectively range 11-13 years old and range 14-17 years old.

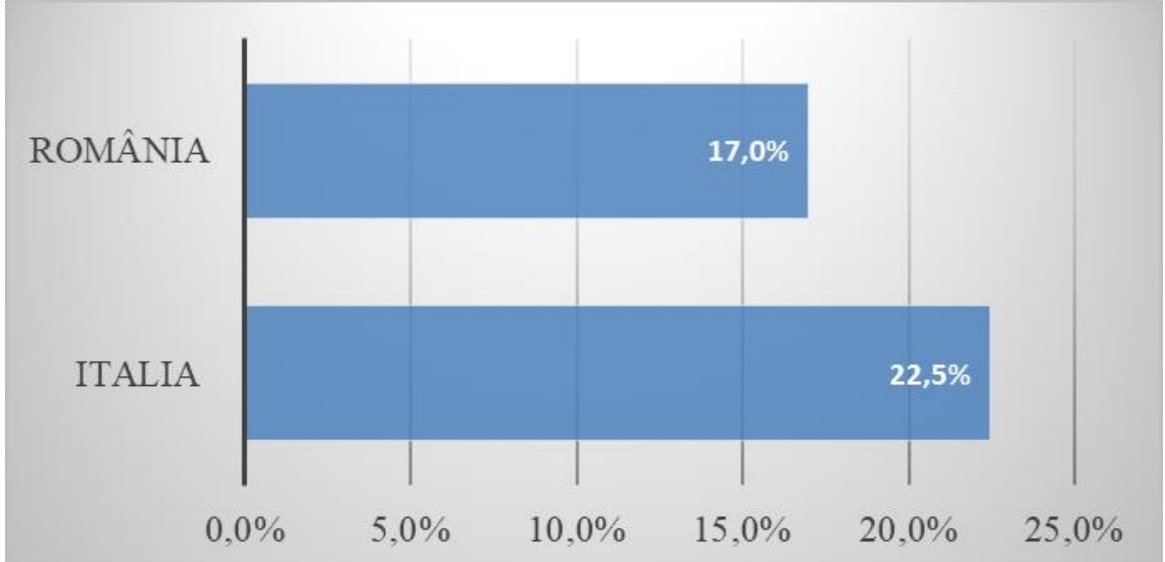

Fig. 1. A comparison between Romania and Italy, related to the bullying phenomenon recorded for the range 11-13 years old

Figure 1 illustrates the percentages of bullying existence in the age range 11-13 years old, in Italy and Romania. It is visible that Romania is situated under Italy, at a difference of $5.5 \%$. The children had certain offensive behaviors, both verbal and physical, from other colleagues, during the school year.

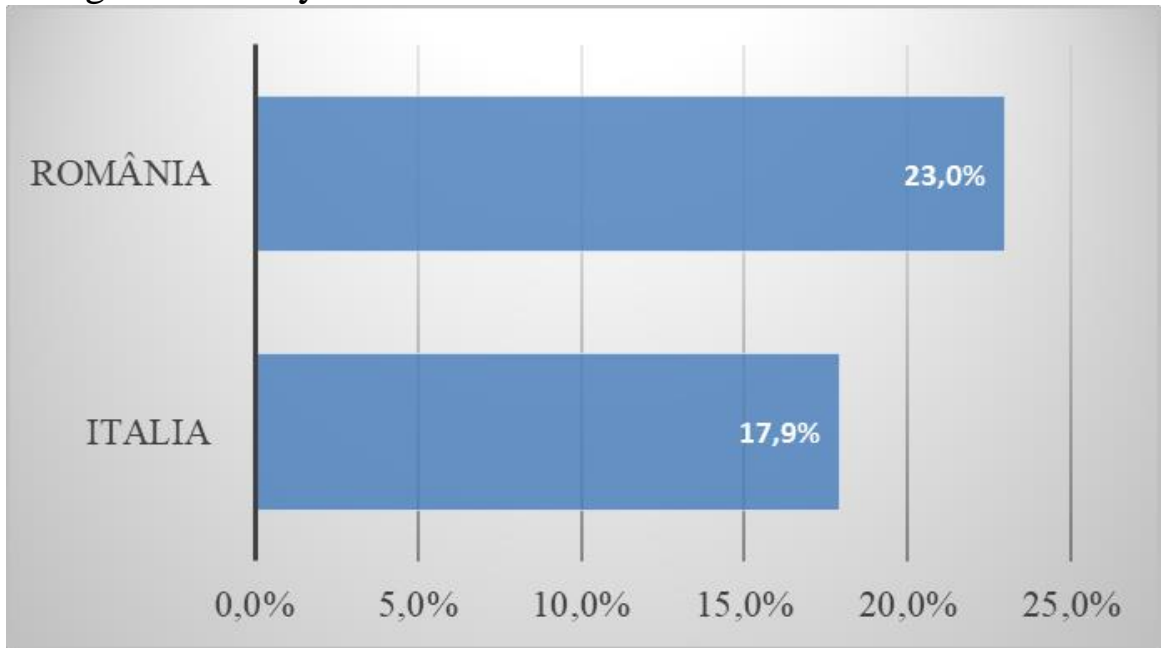

Fig. 2. A comparison between Romania and Italy, related to the bullying phenomenon recorded for the range 14-17 years old

Figure 2 illustrates the percentages of bullying existence in the age range 14-17 years old, in Italy and Romania. In this case, Romania is situated over Italy, at a difference of $5.1 \%$. The adolescents had constantly suffered offensive, humiliating, and violent behavior from other colleagues during the school year. 


\section{THE MICRO-RESEARCH}

\subsection{Proposed hypotheses}

We investigated how the bullying phenomenon is manifested, at the level of several school units from Dâmbovița County, Romania, advancing the following hypotheses:

- if frequent situations of bullying are identified at the level of the school institution, then it is efficient to design and implement strategies to combat or reduce the phenomenon.

- if isolated situations of bullying are identified at the level of the school institution, then it is efficient to design and implement mainly strategies to prevent the phenomenon.

For research, a survey based on the questionnaire was used. The sample under investigation was composed of 92 people from several schools (middle school and high school) from Dâmbovița County, Romania, between November - December 2019. The purpose of the questionnaire was to identify, in percentages (\%), the cases of bullying, and to find places where the victims are assaulted. This can lead to propose necessary measures to prevent or fade the bullying phenomenon. The measures are not be taken at random, but only after prior analysis of the data, by the teachers who are members in the School Board, following the development of the programs that aim to prevent the bullying phenomenon.

The questionnaires were directed to students, in the classrooms, at the same time. The teachers coordinated the process of questioning and collaborated on explaining to students the importance of honestly completing. The role of the questionnaire was to highlight the current situation in schools, by asking six questions to students of different classes.

Highlighting students' knowledge about the bullying phenomenon was introduced by the first question. Here, the students must check if they know what does bullying means, or if this is a term unknown to them.

Question number two was addressed in order to highlight the percentage of students who have had and have not had acts of bullying in the last 30 days.

The periodicity in which the bullying phenomenon manifests itself was deduced from the answer to question number three - by ticking a single variant, the students present the frequency of occurrence of the cases of aggression on them.

When the phenomenon manifests itself, it was important to know the type of behavior that manifests itself - it differs from insults to physical aggression, this fact being established with the help of the question number four.

Question number five determined - in percentage - the places where psychological, verbal, and physical aggression took place.

The last question is comprehensive for people who have witnessed various acts of bullying in school, thus highlighting a category of people who have witnessed or not those acts of harassment.

\subsection{Results}

The results are concentrated in Table 1.

Table 1. Centralization of students' feedback concerning the bullying phenomenon

\begin{tabular}{|c|c|cc|c|}
\hline No. & Question & Answer variants & Percentage \\
\hline \multirow{2}{*}{1} & $\begin{array}{c}\text { What do you think } \\
\text { that bullying is? }\end{array}$ & $\begin{array}{c}\text { a) } \\
\text { b) } \\
\text { of random quarrel between colleagues } \\
\text { of } \begin{array}{c}\text { Insults, offense, denigration, derision } \\
\text { happened intentionally and frequently }\end{array}\end{array}$ & $0 \%$ \\
\hline
\end{tabular}




\begin{tabular}{|c|c|c|c|}
\hline \multirow{2}{*}{2} & \multirow{2}{*}{$\begin{array}{l}\text { Have you had } \\
\text { verbal or physical } \\
\text { aggression in the } \\
\text { last } 30 \text { days? }\end{array}$} & Yes & $33 \%$ \\
\hline & & No & $67 \%$ \\
\hline \multirow{4}{*}{3} & \multirow{4}{*}{$\begin{array}{l}\text { How often do you } \\
\text { get assaulted? }\end{array}$} & a) Daily & $0 \%$ \\
\hline & & b) Weekly & $7 \%$ \\
\hline & & c) Monthly & $18 \%$ \\
\hline & & d) It does not happen to me & $75 \%$ \\
\hline \multirow{3}{*}{4} & \multirow{3}{*}{$\begin{array}{c}\text { What aggressive } \\
\text { behaviors have you } \\
\text { suffered? }\end{array}$} & $\begin{array}{l}\text { a) Swearing, insults, humiliation, ridicule } \\
\text { of physical appearance etc. }\end{array}$ & $31 \%$ \\
\hline & & b) Fists, palms, kicks, pushes etc. & $6 \%$ \\
\hline & & c) It does not happen to me & $63 \%$ \\
\hline \multirow{4}{*}{5} & \multirow{4}{*}{$\begin{array}{c}\text { Where do those } \\
\text { aggressions take } \\
\text { place? }\end{array}$} & a) In the schoolyard & $27 \%$ \\
\hline & & b) In classes & $21 \%$ \\
\hline & & On school halls, in breaks & $30 \%$ \\
\hline & & d) In parks & $22 \%$ \\
\hline \multirow{2}{*}{6} & \multirow{2}{*}{$\begin{array}{l}\text { Have you ever } \\
\text { been present at } \\
\text { such episodes in } \\
\text { your school? }\end{array}$} & Yes & $72 \%$ \\
\hline & & No & $28 \%$ \\
\hline
\end{tabular}

\subsection{Discussion}

Following the application of the questionnaire, it was highlighted that the phenomenon of bullying is alive in schools, therefore it can be considered that both hypotheses mentioned before were met. It is obvious that preventing and combating/reducing the bullying phenomenon is strongly necessary.

Bullying prevention activities can be designed as teaching strategies or curricular activities, which target certain educational and cognitive objectives, mostly on how such activities are carried out promote positive relationships and the development of pro-social skills. The organization of those activities is very important, as may involve a class of children or more, being proposed during the school year, when deemed necessary.

The teaching materials can be created starting from an explanation of bullying phenomenon, enriched with the experience of teachers in their classes, or exploiting the teachers' knowledge gained in dedicated training courses. Here the example of Italian teachers is relevant, as they participated in training courses organized by the Blue Telephone Association.

Special attention has to be paid to victims, by raising the attention of potentially positive colleagues, who often remain indifferent, acting in parallel with the aggressor as passive supporters or neutral observers. Some people are not directly involved, but - through the attitude of indifference - favor the perpetuation of the phenomenon: they are the silent majority who even if they do not approve the aggression, they tolerate it and do not intervene in the defense of the victim.

The objectives of such activities target on valuing the students as "exchange agents", using the positive resources of the class and the natural abilities of children to feel 
compassion for the colleagues in difficulty. It is important to discourage the aggressor and the fact that there are no spectators to applaud, but they are all in the defense of the victim. bullying:

Here are also some examples of proposed activities designed for the prevention of

1. "Friendship bracelet"

Place of activity: school.

Participants: high school students and middle school students involved in this activity.

Description of the activity: the students are divided into groups of two and create bracelets made of colored threads, sealing the friendship. They discuss their recent experiences and highlight positive behaviors and attitudes. The extent to which the activity helps to increase the sense of security in the school is discussed.

Responsible: collaborators.

Beneficiaries: students.

Assessment methods: discussion on how the students felt when they stayed to work together, what difficulties they encountered and how they were helped.

2. "Adoption experiment"

Place of activity: school.

Participants: high school and middle school students involved in the activity.

Description of the activity: In order to diminish the bullying phenomenon in school, "old" students - from grades IX-XII - become "older brothers and/or sisters" for their younger fellows. The "old" students assume responsibilities: counselors, guidance, unconditional support, encouragement. They are models for "younger siblings" throughout the school year. Friendship is sealed by making a symbol, in practical applications. The "older siblings" assume their collective commitment through an oath, in front of the teachers. The aim is to identify bullying, types of violence in school, and to discuss measures to prevent the phenomenon.

Assessment methods: questionnaire.

\section{3. "Words that hurt"}

Place of activity: school.

Participants: middle school and high school students.

Materials needed: Adhesive tape, sticky sheets, pens, or pencils.

Description of the activity: stickers and pencils are distributed to the students. Students are asked to write on the sticky sheets the rude and abusive comments, nicknames, insults they have heard about other students (without indicating or writing the student's name). The adhesive tape is placed on the classroom floor and the following grid/ladder is marked: light jokes or teasing, humiliating jokes, painful insults, very painful insults. Students complete those sheets without talking to each other, and each student sticks them on the adhesive tape next to the ladder/grid considered most appropriate.

Many of the words are repeated and placed on the scale or gradation in different positions. After placing the students in the bench and gluing all the sheets, they are asked to carefully observe the graduated tape. It is reflected, guiding the discussion with the students, to the following questions:

- Have you seen words of the same type in several positions on the scale/gradation?

- Why do you think that some of you considered a word less offensive while others see the same word as painful or humiliating? 
- Does it matter who uses the word and how - or in what context - is used?

- Why are such words used?

- Are there words that are used only for girls and others only for boys?

- What are the most insulting words, and in what category do they fall (girls/boys)?

The teacher, in this case, has to explain why the same word is more offensive or insulting, explain that it depends a lot on the context in which it is said, how it is expressed, the intention which is said, the tone which is pronounced, the facial expression, the influence on how the word is perceived, good or bad.

Identifying the case and the aggressor in class is particularly important, and the adult attitude towards the highlighted phenomenon consists of developing intervention programs and continuous monitoring over time. There must also be a close collaboration of all those responsible for well-being: children (teachers, parents, psychologist, school-staff etc.). In the case of adolescents, they are already trained, and if they have aggressive verbal and physical behaviors, the chances of a teacher or expert succeeding in changing the situation are quite low, or at least one can try an incisive intervention in training.

\section{CONCLUSIONS}

Any objective proposed for combating or reducing bullying, after the identification of a case, has to target on emphasizing the support of collaborative behaviors between students and school. As long as there is collaboration, there is a common interest.

Creating a collaborative class is not an easy task, as it requires high energy consumption, and difficulties can be encountered in order to achieve such objective because it is not enough to bring several students together, but it is also necessary to create an atmosphere of collaboration. Encouraging collaboration allows changing hostile attitudes that exist in the classroom, helping reduce difficulties in studying and integrating students with problems (aggressor and victim).

However, due to the magnitude of the bullying phenomenon, it is necessary to develop a legislative framework to prohibit bullying in schools, and according to its provisions, any behavior that consists of psychological violence must be prohibited.

An important measure to combat this phenomenon can be the training of teachers, in training sessions concerning psychological violence. More, a proper solution is represented by the installation of surveillance cameras in schools and/or the permanent presence of surveillance staff.

\section{BIBLIOGRAPHY:}

[1] Arseneault, L., Bowes, L., \& Shakoor, S. (2010). Bullying victimization in youths and mental health problems: "Much a do about nothing?". Psychological Medicine, 40(5), 717-729

[2] Olweus, D. (1991). Bully/victim problems among school children: Basicfacts and effects of a school-based intervention program. In: K. Rubin, \& D. Pepler (eds.), The development and treatment of childhood aggression (pp. 411-488). Hillsdale, NJ: Erlbaum

[3] Olweus, D. (1993). Bully/victim problems among schoolchildren: Long-term consequences and an effective intervention program. In: S. Hodgins (ed.), Mental disorder and crime (pp. 317-349). Thousand Oaks, CA:Sage

[4] Open Your Wings (2018). Il bullismo in cifre. Gli inquietanti dati del bullismo. Available at: https://www.noisiamofuturo.it/2018/03/18/il-bullismo-in-cifre/

[5] Redatione Salute (2018). Studio dell'ISTAT: In Italia un adolescente su due subisce episodi di bullismo. Available at: https://www.corriere.it/salute/pediatria/18_aprile_21/italia-adolescente-duesubisce-episodi-bullismo-45f0db98-457b-11e8-ae70-70c19cb6c123.shtml 
[6] Salvați Copiii (2016). Despre bullying. Available at: https://www.salvaticopiii.ro/sciro/files/97/97e2ec93-2e52-4536-9aaa-4ddec594008d.pdf

[7] Smith, P. K., \& Thompson, D. (1991). Practical approaches to bullying. London: David Fulton

[8] S.O.S. Il Telefono Azzurro Onlus (2016). Bersagli senza difese? Non lasciamoli soli. Dossier Bullismo e Cyberbullismo - Anno scolastico 2015-2016. Available at: http://www.vita.it/attachment/384254ea-0473-4793-9ee7-4ae77dbb35a7/ 